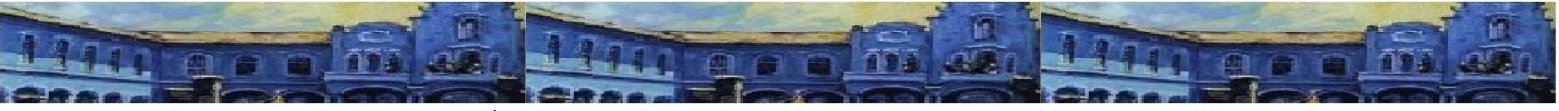

\title{
O RETORNO DE JOVENS E ADULTOS AOS ESTUDOS FORMAIS APÓS 20, 30, 40 ANOS $^{1}$
}

\begin{abstract}
André Boccasius Siqueira²
Resumo: Este texto tem como objetivo principal promover uma reflexão acerca das razões que homens e mulheres adultas retornam à escola, aos bancos escolares, após muitos anos fora do ambiente escolar. Espaço esse com muitas peculiaridades, ou seja, regras, horários a serem cumpridos, tarefas a serem realizadas fora dos horários de aula com prazos estipulados para a entrega, ou seja, as tarefas escolares. Para tanto, realizouse uma pesquisa com estudantes da Educação de Jovens e Adultos em três escolas localizadas na cidade de São Leopoldo/RS. As etapas pesquisadas foram da terceira à quarta, referentes às séries finais do Ensino Fundamental. A pesquisa deu-se através de três questões fechadas, em que os estudantes tinham que expor a opinião pessoal, sem a interferência do pesquisador. A primeira questão referente ao último ano em que estudou, a segunda acerca de quem o estudante recebe incentivos para estudar e o que dizem ao incentivá-lo e, por fim, o estudante revela o porquê está estudando, o que o motiva a estudar e suas expectativas na EJA. No final faço uma apresentação de minha leitura, uma breve reflexão, a partir das respostas fornecidas pelos estudantes, em que o principal foco que se revela são as Políticas Públicas para a Educação de Jovens e Adultos - EJA - uma vez que aparecem nas contribuições dos estudantes, quais sejam o Mundo do Trabalho, as preocupações com o futuro, o tempo perdido fora da escola e as relações interpessoais.
\end{abstract}

Palavras-chave: Educação de Jovens e Adultos; Políticas Públicas para a Educação de Jovens e Adultos; Retorno aos estudos; Auto-estima.

\footnotetext{
${ }^{1}$ Uma versão deste texto foi apresentada na Reunião da ANPEDSul em 2006, ocorrida na cidade de Santa Maria/RS.

${ }^{2}$ Endereço eletrônico: aboccasius@yahoo.com.br. Doutorando em Educação (UNISINOS).
} 
O presente texto é um excerto da proposta de tese defendida na ocasião da seleção para o curso de doutorado em Educação na Universidade do Vale do Rio dos Sinos UNISINOS, São Leopoldo/RS. Na ocasião foi defendido que, de um modo geral, os estudantes da modalidade de Educação de Jovens e Adultos possuem muitas expectativas com seu retorno à escola, aos bancos escolares, na categoria de estudantes, não somente como pais dos alunos das séries ditas regulares ou como servidores e sim como os próprios alunos. Expectativas essas que perpassam as fronteiras da escola e traz para a discussão algumas metas estabelecidas para a educação de países com alto índice de analfabetismo dentre aqueles cidadãos com idade acima de 15 anos, conformes índices apresentados nas Conferências Mundiais de Educação, em Jomtien, Tailândia (1990) e em Dakar, Senegal (2000), ambas promovidas pela UNESCO - Organização das Nações Unidas para a Educação, Ciência e Cultura, UNICEF - Fundo das Nações Unidas para a Infância, PNUD - Programa das Nações Unidas para o Desenvolvimento e, Banco Mundial; e apresentadas por Torres, 2001.

Para que melhor possa expressar as idéias que trago para a reflexão, divido o presente texto em três partes, na primeira - algumas idéias sobre a EJA - apresento algumas considerações sobre a modalidade de Educação de Jovens e Adultos, na segunda - $a$ pesquisa realizada em três escolas públicas da cidade de São Leopoldo - as respostas dos estudantes, onde faço um breve comentário a partir de cada grupo de respostas. A terceira parte - políticas pública para EJA - trago alguns excertos das políticas públicas para a educação e suas influências na modalidade de Educação de Jovens e Adultos juntamente com breves reflexões acerca do tema em foco.

\section{Algumas idéias sobre a EJA}

Quanto à modalidade Educação de Jovens e Adultos, esta foi criada pela Lei de Diretrizes e Bases da Educação Nacional n. 9.394/96, artigo 4으, incisos I ao XI; e artigos 37 e 38 que a regulamentam com o intuito de substituir a modalidade de suplência [existia para que o estudante fosse preparado para realizar as provas de supletivo organizadas pelas Secretarias Estaduais de Educação. As referidas provas ainda existem, uma vez que é regulamentada pela $\mathrm{LDB} / 96]$.

A EJA possui a estrutura curricular aberta e a metodologia é diferenciada em relação ao ensino dito regular. A metodologia utilizada é dialógica e parte-se dos saberes que estes 
estudantes já possuem. Refiro-me aos saberes populares, aos saberes detidos pela comunidade escolar em seu cotidiano, trazidos pelos estudantes para a sala de aula para que sejam ampliados com os saberes escolares, saberes estes, socialmente aceitos e legitimados pela sociedade, sendo considerados como "um conjunto de conhecimentos inteligíveis" (SIQUEIRA, 2004, p. 39), ou seja, não cientifizado.

Em se tratando de aprendizagem, o tempo nesta modalidade de ensino é subjetivo. É outro ponto que EJA diferencia-se do ensino regular. Cada estudante faz seu tempo de estudo, de aprendizagem. Se seu ritmo é mais acelerado, seu avanço para outra etapa será anterior com relação àquele colega cujo tempo de aprendizagem precisa ser maior.

Esse adulto que retornou ao ambiente escolar por diversos motivos, dentre eles porque o mercado de trabalho exige uma escolarização que o estudante não possui; em busca de saber escolarizado ou para contribuir nos deveres (temas de casa) dos filhos, dos netos ou, ainda, porque os filhos já estão na adolescência ou na idade adulta - como eles mesmos dizem "os filhos já estão crescidos" - e não precisando mais de tanta atenção dos pais, podendo, então, investir na escolarização de si mesmos. Isso acontece, geralmente, quando o casal procura a escola e, juntos, enfrentam o grande desafio de retornar aos bancos escolares. Com isso, melhora a auto-estima de ambos e um apóia o outro superando as dificuldades do colega.

A pesquisadora Giovania Lúcia dos Santos $(2003$, p. 11) utiliza o termo "escolarização tardia" para designar os estudantes da Educação de Jovens e Adultos que retornam à escola a fim de continuar os estudos, interrompidos quando crianças por diversos motivos ou para iniciar sua escolarização formal, ou seja, para se alfabetizar. Muitas vezes, em conversas informais dentro e fora da sala de aula e sem o exercício do poder ou mesmo tentando ameniza-lo (professor \& aluno/a) descobre-se que os estudantes desta modalidade de ensino entraram precocemente no mercado de trabalho, muitas vezes abandonando a escola para trabalhar na roça com seus pais, na cozinha para que quando seus irmãos mais velhos e pais retornassem à residência, oriundos da fábrica ou da roça, o alimento já estivesse preparado. Ou ainda, uns iam trabalhar nas fábricas a fim de receber um salário e contribuir no provimento financeiro da família e outros ficavam em casa para suprir as necessidades da mesma, tais como cozinhar, lavar roupas, passar roupas, cuidar dos irmãos mais novos, arrumar a casa, enfim, os afazeres domésticos diários que eram dispensados principalmente aos membros dos sexo feminino e jovens ou crianças. 


\section{A pesquisa realizada em três escolas públicas da cidade de São Leopoldo}

Para o levantamento dos dados, solicitei que os estudantes respondessem a algumas questões, e que me autorizassem a divulgá-las sob a forma de um trabalho a fim de sabermos o perfil dos estudantes da EJA daquelas instituições. Todos estavam cientes de que suas respostas não precisavam de qualquer outro tipo de identificação pessoal, tanto que em nenhum momento faço referência a esse dado. Não houve a interferência do pesquisador nas respostas. Após os acordos, combinamos que os estudantes fossem sinceros em suas respostas.

Inicialmente os estudantes responderam uma questão simples que trata de indicar quanto tempo está fora da escola. As respostas foram muito variadas, desde um até mais de 40 anos. Nesta questão foi evidenciado que a etapa três, referente ao sexto ano ou quinta série $^{3}$ é a que apresenta os estudantes mais tempo afastados da escola e que a oportunidade hoje aproveitada pelos mesmos é impar em suas vidas.

Muitos deles retornam aos estudos por diversos motivos, entre eles a abertura de uma escola noturna próximo a suas casas. Para as pessoas que sempre residiram no perímetro urbano parece ser esse um fato sem muita importância, porém, àqueles que viveram no interior das cidades rurais ou mesmo urbanas, e que havia uma escola multisseriada que oferecia escolarização até a quarta série ${ }^{4}$ e, a continuidade de seus estudos ficava muitos quilômetros de distância e sem recursos familiares para o deslocamento. Nos dias atuais, ter uma escola perto de sua residência é de muita importância para a continuidade de seus estudos, para dar significados às suas vidas e seus sonhos de um futuro melhor para si e para seus filhos. Portanto, alguns dos estudantes relataram que se sentem felizes por estarem retornando à escola 20,30, 40 ou mais anos depois...

Nas respostas dos estudantes, verifica-se que as vivências são muito diferentes na mesma etapa/turma das três instituições pesquisadas, com estudantes saindo do ensino dito regular no presente ano ou no anterior, bem como alunos com mais de 40 anos sem estudar formalmente. $\mathrm{O}$ número de jovens e adultos trabalhadores que retorna aos bancos escolares

\footnotetext{
${ }^{3}$ Quando da realização da pesquisa, o Ensino Fundamental era composto por oito anos. A partir da Lei $n$. 11.274, de 06 de fevereiro de 2006, o Ensino Fundamental passou a ter nove anos. Agregou-se um ano a mais nesta etapa da escolarização.

${ }^{4}$ Segundo a nova legislação, o quinto ano.
} 
após interrupções ou fracassos na escolarização regular é historicamente elevado em nosso país. Nos últimos anos há um incentivo maior aos municípios e estados para que ofereçam o ensino formal aos estudantes jovens e adultos inseridos ou não no mercado de trabalho. Para melhor compreendê-los, a próxima questão refere-se aos incentivos que recebem.

Quanto ao incentivo que recebem, os estudantes das três escolas pesquisadas são, em sua maioria, em torno de $60 \%$ valorizados pela família, com palavras que elevam a autoestima dos mesmos. Aproximadamente 20\%, responderam que a iniciativa veio de si próprio, uma das entrevistas colocou que o "marido odiou a decisão de estudar" e outra que "depois de estar estudando é que o marido concordou que ela retornasse aos estudos". Quase 20\% são incentivados pelos empregadores, por amigos, por colegas e por professores de anos anteriores. Dois estudantes responderam que não recebem incentivos, não lembraram, como se pode observar, nem de si próprios, do autoincentivo.

Um dos estudantes deixa claro que "desde muito tempo vinha alimentando a idéia de estudar", mas tomou a iniciativa porque "o mercado de trabalho está pedindo" qualificação. A grande maioria recebe como incentivo a idéia de que tem sobre a "importância para o futuro". Esse futuro com vistas ao mercado de trabalho e com a ilusão de que com estudos a vida vai melhorar, e que tudo vai mudar... Uma esperança de mudança que, quando nos damos conta, temos que estudar cada vez mais. Outros estudantes afirmam que "nunca é tarde para estudar". Certamente são incentivos às pessoas que estavam mais tempo fora da escola e que, por seus motivos, resolveram estudar, continuar os estudos. Retornar aos bancos escolares e ter novas chances no mercado de trabalho, agora com uma escolarização formal mais intensa.

Nesta questão, os estudantes podiam lembrar de várias fontes de incentivo. Não havia alternativas para marcar. Apenas a pergunta aberta. A questão refere-se ao incentivo recebido pelos estudantes. Fica claro, nas respostas, que a família é a principal fonte de incentivo das pessoas entrevistadas. Em segundo lugar, enfatizam que a vontade vem de si próprios/as e a referência aos amigos e colegas.

Compreendendo um pouco mais acerca dos motivos que levaram esses estudantes a procurar a Educação dos Jovens e Adultos, a próxima pergunta fez essa referência. Um dos motivos é o de que o mercado de trabalho exige profissionais mais qualificados e escolarizados. A família, sentindo essas dificuldades, trata de incentivar os mais jovens para que não passem por dificuldades futuras e os mais velhos para que as dificuldades do dia a 
dia diminuam. Os estudantes com mais idade, que (re)iniciam sua escolarização já sentiram a falta de estudos formais em suas atividades laborais. Ao mesmo tempo, alguns recebem um (des)incentivo dos familiares, como colocou a estudante cujo marido não aprovou sua decisão, mas consentindo quando a esposa manteve-se firme em seu propósito, de concluir a Educação Básica.

Quanto aos motivos que os estudantes estão estudando, foram vários os relatados pelos mesmos, uma vez que há uma grande relação com o Mercado de Trabalho, com a Aquisição de Conhecimentos e Relações Interpessoais. Há a idéia de que fora da escola não existe conhecimento ou que com o ensino formal a vida será melhor, ou que haverá mudanças significativas em suas vidas com a conclusão do Ensino Fundamental.

As respostas referentes ao Trabalho estão relacionadas a novas chances no mercado laboral: "arrumar um emprego melhor", "um melhor trabalho", "quero um trabalho fixo", "conseguir um emprego", "manter o emprego", "melhorar profissionalmente", "colocar meu próprio negócio", "progredir na vida, trabalhar e estudar, se dar bem na vida", "mudar a minha vida e de outras crianças porque pretendo ser professora do pré...", "vencer, crescer, aprender e fazer bons amigos, conseguir mais qualidade no meu trabalho", "passar de ano e arrumar um serviço melhor".

As respostas relacionadas com os Conhecimentos proferidas pelos participantes da pesquisa são: "ter mais conhecimentos e cultura", "busca de conhecimentos", "incentivar e dar exemplo aos/às filhos/as", "incentivar os netos", "continuar estudando", "terminar o ensino fundamental", "aprender mais", "abrir a minha cabeça para o que está acontecendo no mundo da matemática, história, português e até falar melhor", "poder ajudar meus filhos porque às vezes ele pedem minha ajuda e eu não sei", "recuperar o tempo perdido fora da escola", dentre outros. Enfim, os estudantes acreditam na instituição escolar e que ela poderá contribuir substancialmente para ampliar de suas possibilidades de inserção no mercado de trabalho através dos conhecimentos ditos formais aprendidos na escola, bem como tais conhecimentos poderão favorecer o desenvolvimento de novas possibilidades de inserção ou afirmação de seu emprego.

Outras respostas relacionadas na categoria de Relações ou Esperanças de um futuro melhor, tais como "ser alguém na vida", "mudar de vida", "ter uma noção das coisas que acontecem ao meu redor", "ajudar financeiramente a família", "oferecer algo melhor para a família", "falar melhor com as pessoas", "não ter medo quando procurar um emprego", 
"melhorar o futuro", "um futuro melhor pra mim e para os meus filhos", "ajudar as outras pessoas ensinando", "ajudar muita gente; poder ajudar meus filhos porque às vezes eles pedem minha ajuda e eu não sei", "para nosso crescimento interno", "terminar meus estudos e, se possivel, fazer uma faculdade" e "aumentar a auto-estima", "ser feliz".

A idéia de que a escolarização mais avançada lhes dará um melhor entendimento do mundo fora da escola, como se a escola estivesse descolada da sociedade, está presente em muitas respostas dos estudantes, uma vez que alguns dizem que precisam "recuperar 0 tempo perdido", tempo esse de suas juventudes não aproveitadas, quando não permaneceram frequentando o espaço escolar e tiveram que entrar, prematuramente ou não, no mercado de trabalho. Alguns entendem que possuindo uma escolarização melhor da que detém hoje, podem conseguir melhor emprego, uma profissão mais qualificada e um emprego que lhes dê uma melhor qualidade de vida. Nas palavras deles "melhorar de vida". O que não deixa de ser um objetivo de vida a ser alcançado pelos estudantes, uma vez que desenvolvem a criticidade a medida em que adquirem novos conhecimentos, novas relações entre seus saberes com os saberes escolarizados, pois os horizontes ampliam e conseguem perceber além dos seus horizontes atuais, seja pelos conhecimentos formais da escola, o dito conhecimento escolar.

A idéia de que não detém cultura, está também presente nas escritas desses estudantes. O conhecimento escolar é muitíssimo valorizado por quem está fora da escola. A desvalorização de seus saberes faz com que considerem a escola como uma instituição de difícil alcance. Esse é um dos motivos que a procuram somente nesta fase de sua vida. Ao mesmo tempo, a academia está preocupada em valorizar os saberes locais, a população está preocupada em saber em que a academia está falando, estudando ou envolvendo-se (CHASSOT, 2001).

Outra leitura que faço acerca das respostas dos estudantes, ainda sobre a valorização dos estudos, é que aqueles com família formada, preocupam-se com os descendentes, quando dizem que querem dar o exemplo aos filhos ou aos netos. Acreditam que dessa forma podem incentivar os familiares a continuar estudando. As relações familiares, com esse ato, são fortalecidas, tendo em vista que os pais-estudantes contribuem ativamente para que os filhos-estudantes também consigam um bom desempenho escolar.

Identifico, para esta reflexão, as respostas "ser alguém na vida" e "mudar de vida" como um desabafo dos mais jovens, que entraram no mercado de trabalho há poucos anos e 
que estão sentindo que, com pouca escolarização, não conseguem os melhores trabalhos, as melhores tarefas, ao empregarem-se nas empresas da região, sobretudo relacionados com a metalurgia e com a fabricação de calçados. Almejam oportunidades melhores para si e sua família. Depositam muitas esperanças na instituição escolar, após o recebimento do certificado de conclusão do Ensino Fundamental e/ou Médio, e que esse saber que estão em busca, Ihes proporcione um sentimento de felicidade, sentimento esse que tem a esperança de conseguir após esse período escolar. Porém, terão que se dar conta de que esse sentimento está dentro de si, não fora, não apenas em um certificado.

\section{Políticas Públicas para a EJA}

O surgimento da modalidade de Educação de Jovens e Adultos, criada pela Lei de Diretrizes e Bases da Educação Nacional n. 9.394/96, não foi por acaso ou devido a boa vontade dos governantes daquela época. Trata-se de um acordo que o país fez com agências financiadoras, como o Banco Mundial que estipulava que os países com baixíssimo índice de indivíduos, acima de 15 anos, alfabetizados, elevassem tal índice em um período de dez anos. O Brasil enquadra-se nesse grupo. Dos 155 países que participaram da Conferência Mundial de Educação para Todos, um Jomtien (Tailândia), em 1990, o Brasil ficou entre os nove países com maior taxa de analfabetismo, formando, para nosso desprazer, o grupo denominado "EFA - 9" (SHIROMA, MORAES e EVANGELISTA, 2002). Após essa conferência, muitos países mobilizaram-se para promover reuniões e ações para minimizar tais índices. 0 governo brasileiro e os estados federativos mobilizaram-se a fim de promover debates internos acerca da educação básica. Esses encontros envolveram educadores de todo o país e, em dezembro de 1996 foi votada no Congresso Nacional a nova Lei de Diretrizes e Bases da Educação Nacional e posteriormente sancionada pelo Presidente da República. Lei essa criada para durar mais de dez anos e suprir os acordos firmados pelo Brasil com o Banco Mundial e outros órgãos de fomento da educação e desenvolvimento da infância. Foi aí que se criou a já comentada modalidade de EJA, com suas peculiaridades (já comentadas na primeira parte deste texto).

Em 2000, houve nova conferência para avaliar os dez anos após Jomtien e planejar os próximos 15 anos. Essa nova conferência foi realizada em Dakar, no Senegal. Foi promovido pela Organização das Nações Unidas - ONU. Os 196 países participantes realizaram vários acordos, dentre outros, que pouco havia sido avançado. Dentre os aspectos "combinados" 
na reunião, está a redução em $50 \%$ do índice de analfabetismo entre adultos até o ano de 2015.

No Brasil, o Plano Nacional de Educação - PNE - prevê, entre outros pontos, para a EJA, o "treinamento de imensos contingentes de jovens e adultos para inserção imediata no trabalho" e "criar oportunidades de educação ao longo da vida, ou educação permanente" (REDIN e MORAES, 2001). Nas falas dos estudantes, transcritas anteriormente, aparece claramente que há esperança de melhores oportunidades de trabalho ou mesmo um trabalho formal, com a sua inserção destes profissionais na escola. Tais expectativas estão harmonizadas com o referido Plano.

\section{Uma reflexão para encerrar}

Para o sistema econômico a que estamos inseridos, quanto mais rápido os estudantes concluírem seus estudos, menos tempo estarão em contato com a escola formal. Isso quer dizer que não aprofundam os conteúdos programáticos, ou seja, os estudam superficialmente e mesmo aqueles estudantes que não alcançam os objetivos mínimos para cada etapa da escolarização, recebem o certificado de conclusão, juntamente com aqueles que se esforçam nas atividades escolares. Para o pesquisador Canclini (1995, passim), é mais fácil de manipular consumidores com pouca instrução do que cidadãos que pensam, que refletem sobre seu agir na sociedade.

Questiono-me acerca da modalidade de EJA: Será que a Educação de Jovens e Adultos não está a serviço desse sistema que muitos de seus educadores contestam? Como está sendo a prática desta modalidade? Os estudantes que entram são, na mesma quantidade os que se formam, ou que concluem a Educação Básica?

Certamente não conseguirei responder a todas as questões, porém, tentarei buscar em Michel Foucault o que penso. Quando não conseguimos nos enquadrar ao ambiente em que estamos, há mecanismos para que nos mostrem que estejamos cientes de que somos os diferentes. Para Michel Foucault (2003, p. 36) "a disciplina é um princípio de controle da produção do discurso. Ela lhe fixa os limites pelo jogo de uma identidade que tem a forma de uma reatualização permanente das regras". Regras essas que nem sempre seguimos e mas que são naturalizadas, na instituição escolar. No momento em que tentamos agir por conta própria e somos descobertos realizando algo que não está previsto na norma sob o 
que pode ser feito, sofremos as "punições" por esses atos pensados ou não, mas que são ações próprias da "instituição disciplinar" (HARDT \& NEGRI, 2003, p. 42), que é a escolar.

Nesses termos, vale uma reflexão acerca das relações de poder, em que Foucault (1995, p. 241) coloca que há "a dominação dos meios de coação, de desigualdade e de ação dos homens sobre os homens". Observa-se, na escola, o uso do poder por parte dos professore sobre os estudantes, quando os mesmos não reconhecem os alunos que precisam faltar seguidamente às aulas por ter uma jornada de trabalho muito significativa e, optam pela sobrevivência, contudo, não deixam de ter um sutil vínculo com a instituição escolar. Para o autor “[...] só há poder exercido por 'uns' sobre os 'outros'. O poder só existe em ato, mesmo que, é claro, se inscreva num campo de possibilidade esparso que se apoia sobre estruturas permanentes" (p. 242). Essa relação de poder exercido pelos professores sobre os estudantes, pelos governantes sobre os profissionais de educação, sobre os organismos financiadores da educação, enfim, por vários setores e atores.

Além disso, "o termo 'poder' designa relações entre 'parceiros' [...] um conjunto de ações que se induzem e se respondem uma às outras" (id., p. 246). Enquanto os estudantesadultos estiverem inseridos na instituição, terão que seguir as regras da mesma, em outros termos: enquadrar-se ou ajustar-se ao sistema ou saem dele. Enquanto estiverem inseridos no mesmo espaço, haverá essa relação de poder disciplinador em que, de um lado há o grupo diretivo da escola que prima para que as regras da instituição estejam a todo o instante sendo cumpridas, no mesmo lado o grupo docente que representa a direção na sala de aula e, de outro o corpo discente que também exercem relações de poder, mas que estão sempre sendo vigiados por diversas pessoas.

Acerca da disciplina, vale a pena ressaltar que se liga a "um corpo individual", considerando o indivíduo no "nível do detalhe" (FOUCAULT, 1999, p. 294), "detalhe" esse que o remete a seu um único indivíduo, a disciplina como técnica reguladora do corpo, "centrada no corpo, produz efeitos individualizantes, manipula o corpo como foco de forças que é preciso tornar útil e dócil ao mesmo tempo" (id., p. 297). O estudante é considero um "bom aluno" quando possui um corpo já manipulado, já útil e já dócil. Manipulado porque respeita as regras, realiza todas as atividades propostas pelos professores, funcionários e corpo diretivo da instituição; útil porque está sempre presente para contribuir com sua prestação de serviços à instituição; dócil no sentido de que o estudante "não cause 
problemas" ao andamento da aula. E este indivíduo que ingressa no mercado de trabalho, já manipulado, já conduzido ao sistema laboral.

Neste contexto, a Educação de Jovens e Adultos é uma modalidade que foi criada através da Lei de Diretrizes e Bases da Educação Nacional, em 1996. Até então era tratada, na escolarização nacional, como suplência, como um modo de os estudantes apenas receber o certificado de conclusão da escolarização formal. Hoje as relações são diferentes, a modalidade ganhou status no contexto da educação básica e leva, aos estudantes, novas perspectivas de futuro para uma grande parcela da população brasileira que, até então, estava a parte da educação formal nacional. Hoje são novos escolarizados entrando $n$ mercado de trabalho formal brasileiro.

\section{Referências Bibliográficas:}

CANCLINI, Néstor García. Consumidores e cidadãos: conflitos multiculturais da globalização. Rio de Janeiro: Editora UFRJ, 1995.

CHASSOT, Attico Inácio. Alfabetização Científica: questões e desafios para a educação. ljuí: Ed, UNIJUÍ, 2001. (Coleção educação em química).

FOUCAULT, Michel. O Sujeito e o Poder. In: DREYFUS, H. e RABINOW, P. Michel Foucault: uma trajetória filosófica para além do estruturalismo e da hermenêutica. Rio de Janeiro: Forense Universitárias. 1995. (p. 231-249).

FOUCAULT, Michel. Aula de 17 de março de 1976. In: Em Defesa da Sociedade: Curso no Collège de France (1975-1976). São Paulo: Martins Fontes, 1999. (p. 285-315).

FOUCAULT, Michel. A ordem do discurso: aula inaugural no Collège de France, pronunciada em 2 de dezembro de 1970. São Paulo: Edições Loyola. 2003. (Coleção Leituras Filosóficas).

HARDT, Michael e NEGRI, Antonio. Império. São Paulo: Record. 2003.

REDIN, Euclides, MORAES, Salete Campos de. Políticas públicas de educação básica - um olhar sobre o Plano Nacional de Educação. Educação Unisinos. v. 5, n. 8, 2001. p. 29-48.

SANTOS, Giovania Lúcia dos. Quando adultos voltam para a escola: o delicado equilíbrio para obter êxito na tentativa de elevação da escolaridade. In: SOARES, Leôncio (org.). Aprendendo com a diferença: estudos e pesquisas em Educação de Jovens e Adultos. Belo Horizonte: Autêntica, 2003. p. 11-38.

SHIROMA, Eneida Oto; MORAES, Maria Célia Marcondes de; EVANGELISTA, Olinda. Política educacional. Rio de Janeiro: DP\&A. 2002. (O que você precisa saber sobre...). 
SIQUEIRA, André Boccasius. Aproveitando os saberes de jovens e adultos sobre plantas medicinais. 2004. Dissertação. Mestrado em Educação, Curso de Pós-Graduação em Educação Básica, Centro de Ciências Humanas, Universidade do Vale do Rio dos Sinos, São Leopoldo, 2004.

TORRES, Rosa María. Educação para todos: a tarefa por fazer. Porto Alegre: Artmed, 2001. 